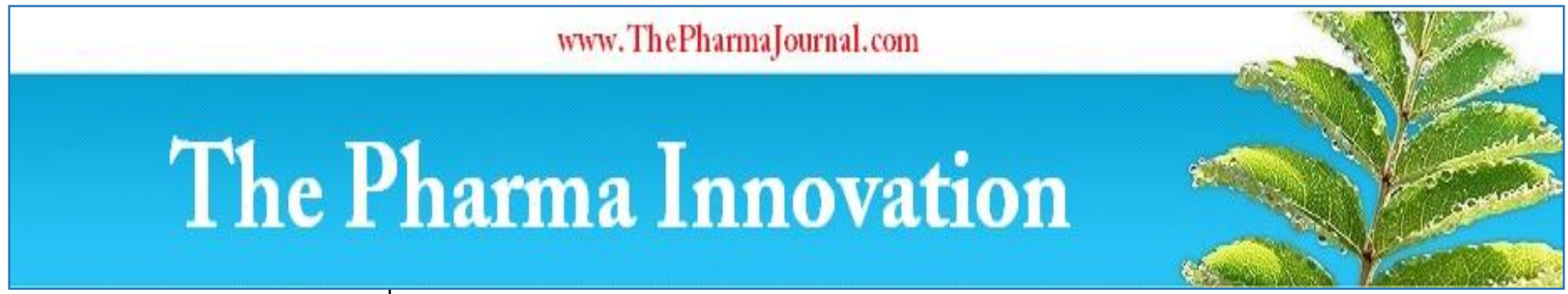

ISSN (E): 2277 - 7695

ISSN (P): 2349-8242

NAAS Rating: $\mathbf{5 . 2 3}$

TPI 2021; SP-10(4): 77-81

(C) $2021 \mathrm{TPI}$

www.thepharmajournal.com

Received: 17-02-2021

Accepted: 28-03-2021

\section{Vijayanand}

Assistant Professor, Resident

Veterinary Services Section,

Madras Veterinary College,

Chennai, Tamil Nadu, India

M Balagangatharathilagar Assistant Professor, Department of Veterinary Clinical Medicine, Madras Veterinary College, Chennai, Tamil Nadu, India
Corresponding Author: V Vijayanand

Assistant Professor, Resident

Veterinary Services Section,

Madras Veterinary College,

Chennai, Tamil Nadu, India

\title{
On field diagnostic and prognostic indicators of pregnancy toxaemia in goats
}

\section{Vijayanand and M Balagangatharathilagar}

DOI: https://doi.org/10.22271/tpi.2021.v10.i4Sb.5972

\begin{abstract}
Periparturient mortality in goats have a great economic impact on the livelihood of marginal farmer. Pregnancy toxaemia in small ruminants occur as a result of negative energy balance consequent to enhanced requirement for glucose by the developing foetuses in the last trimester (last 6 to 4 weeks) of gestation. Among the does treated for various medical conditions at Veterinary University Peripheral Hospital, Madhavaram Milk Colony, Chennai - 51 during the period October 2016 - September 2018, 72 does in their last six weeks of gestation carrying twins / triplets and presented with the history of off feed were subjected to determination of blood beta hydroxybutyric acid (BHBA) level by means of a portable blood ketone and glucose monitoring system and qualitative urinalysis using urine dip stick. Does with beta hydroxybutyric acid level $>0.8 \mathrm{mmol} / \mathrm{L}$ and $<1.6 \mathrm{mmol} / \mathrm{L}$ were classified as sub clinical pregnancy toxaemic group $(\mathrm{n}=12)$ and beta hydroxybutyric acid level $>1.6 \mathrm{mmol} / \mathrm{L}$ were classified as clinical pregnancy toxaemic group $(n=12)$. The control animals were selected from adult Tellicherry does in the age group of 2 to 4 years maintained at Livestock Farm Complex (LFC), Madhavaram Milk Colony, Chennai - 600051 . The pregnancy toxaemic does were resorted to treatment with intravenous glucose therapy ( 5 per cent Dextrose), parenteral therapy of Vitamin $\mathrm{B}_{1}, \mathrm{~B}_{6} \& \mathrm{~B}_{12}$ and oral administration of glycerine @ $25 \mathrm{ml}$ twice daily. All the twelve does of sub clinical pregnancy toxaemic group recovered completely with a cure rate of 100 per cent while in the clinical pregnancy toxaemic group the cure rate was only 33 per cent. On field reliable diagnostic indicators of pregnancy toxaemia include blood $\beta$ hyroxybutyric acid concentration $(\geq 0.8 \mathrm{mmol} / \mathrm{L})$ and presence of ketone body, glucose and protein in urine while hyperglycaemia in advanced pregnancy toxaemic does indicate foetal death.
\end{abstract}

Keywords: Diagnostic and prognostic indicators, on field test, pregnancy toxaemia, goats

\section{Introduction}

Pregnancy toxemia also called gestational ketosis, twin-lamb disease, ketosis of pregnancy, kid disease, lambing sickness, kidding paralysis and lambing or kidding ketosis (Rook, 2000) ${ }^{[13]}$ is a metabolic disease affecting pregnant ewes and does after a period of negative energy balance (NEB) and impaired gluconeogenesis (Lima et al., 2012) [10]. Pregnancy toxaemia normally occur in the last trimester (last 6 to 4 weeks) of gestation in goat and sheep as a result of negative energy balance consequent to enhanced requirement for glucose by the developing foetuses (Schlumbohm and Harmeyer, 2008) ${ }^{[15]}$. Risk factors include multiple fetuses, poor quality of ingested energy, decreased dietary energy level, genetic factors, obesity, lack of good body condition, high parasitic load, stress factors and multiple pregnancies (Hefnawy et al., 2011) ${ }^{[9]}$. The disease is characterized by hypoglycaemia, low concentrations of hepatic glycogen, increased fat catabolism leading to high plasma concentration of non-esterified fatty acids (NEFA), high concentrations of ketone bodies (hyperketonaemia) and high mortality rate (Van Saun, 2000) ${ }^{[16]}$. The mortality rates can attain $100 \%$ even with the initiation of treatment due to severe irreversible organ damage. Hence diagnostic and prognostic indicators of pregnancy toxaemia in the primary stage of the disease are the need of the hour for better herd health management.

\section{Materials and Methods}

The study was carried out at Veterinary University Peripheral Hospital (VUPH), Madhavaram Milk Colony, Chennai - 6000051 and Livestock Farm Complex (LFC), Madhavaram Milk Colony, Chennai - 600051 during the period October 2016 - September 2018. The control animals were selected from adult Tellicherry does in the age group of 2 to 4 years maintained at Livestock Farm Complex (LFC), Madhavaram Milk Colony, Chennai - 600 051. Non pregnant does $(n=8)$ and pregnant does $(n=8)$ carrying twins / triplets, without exhibiting signs of pregnancy toxaemia throughout gestation at Livestock Farm Complex, Madhavaram 
Milk Colony served as control. Seventy two does in their last six weeks of gestation carrying twins / triplets presented with the history of off feed to Veterinary University Peripheral Hospital, Madhavaram Milk Colony, Chennai were subjected to determination of blood beta hydroxybutyric acid (BHBA), glucose concentration by means of a portable blood ketone and glucose monitoring system and qualitative urinalysis using urine dip stick. The pregnant does were subjected to ultrasonography and radiography for conformation of pregnancy, assess the stage of pregnancy and fetal numbers. Does with beta hydroxybutyric acid level > $0.8 \mathrm{mmol} / \mathrm{L}$ and < $1.6 \mathrm{mmol} / \mathrm{L}$ were classified as sub clinical pregnancy toxaemia $(\mathrm{n}=12)$ and levels $>1.6 \mathrm{mmol} / \mathrm{L}$ were classified as clinical pregnancy toxaemia $(n=12)$.

\section{Parameters}

Clinical Signs: The clinical signs exhibited by the pregnant does were recorded.

Body Condition Score (BCS): Body condition score was assessed using a 5 point scale $(1.0-5.0)$ by evaluating the animals visually and by palpating the region of lumbar vertebrae and sternum (Villaquiran et al., 2012) ${ }^{[17]}$.

Blood $\beta$-hydroxybutyric acid (BHBA) concentration: The blood $\beta$-hydroxybutyric acid (BHBA) concentration was determined using a portable blood ketone and glucose monitoring system (Fig. 1) (Free Style Optium Neo H Abbott ${ }^{\circledR}$ ) as suggested by Pichler et al. (2014) ${ }^{[12]}$. The ear vein was punctured with a sterile $23 \mathrm{G}$ needle and the ketone meter attached with blood ketone strip (Fig. 2) was directed towards the drop of blood (Fig.3). Sufficient quantity of blood droplet was absorbed at the tip of the strip by capillary action and within 10 seconds the blood $\beta$-hydroxybutyric acid (BHBA) concentration was displayed on to the digital meter.

Blood Glucose concentration: The blood glucose concentration was determined similar to blood $\beta$ hydroxybutyric acid (BHBA) concentration using the same portable blood ketone and glucose monitoring system (Pichler et al., 2014) ${ }^{[12]}$ attached with glucose test strip (Fig. 4)

Urine sample: Urine samples were obtained after a voluntary micturition or induced by covering the nose and mouth of does for a few seconds (Albay et al., 2014) ${ }^{[2]}$. The urine samples were analyzed using Multistix 10 SG reagent strip (Fig. 5) (Siemens Healthcare Private Limited, India) for qualitative determination of ketone bodies, glucose and protein (Emam and Galhoom, 2008) ${ }^{[7]}$. The test strips were dipped into the collected urine and immediately compared with the colour chart provided on the label of the urine test strip container to determine the presence of ketone, glucose and protein in the urine. (Fig 6).

Ultrasonography: The pregnant does were subjected to ultrasonography to assess the stage of gestation and the viability of the fetuses. The estimated gestational age of the fetus in weeks was calculated using the formula $\mathrm{Y}=4.712+$ $0.445 \mathrm{X}$, where $\mathrm{Y}=$ Gestational age (wks) and $\mathrm{X}=$ Fetal parameter $(\mathrm{cm})$ in case of crown rump length and $\mathrm{Y}=2.675+$ $3.229 \mathrm{X}$ where $\mathrm{Y}=$ Gestational age (wks) and $\mathrm{X}=$ Fetal parameter $(\mathrm{cm})$ in case of bi-parietal diameter (Abdelghafar $e t$ al., 2011) ${ }^{[1]}$.
Radiography: The pregnant does were subjected to radiography to confirm pregnancy and assess the foetal numbers (Fig. 7 \& 8).

Therapy: The pregnancy toxaemic does were treated with intravenous glucose therapy (5 per cent Dextrose) and oral administration of glycerine for 3-4 days @ $25 \mathrm{ml}$ twice daily supported with parenteral therapy with Vitamin $\mathrm{B}_{1}, \mathrm{~B}_{6} \& \mathrm{~B}_{12}$. The response to therapy was evaluated based on the improvement in clinical signs and blood $\beta$-hydroxybutyric acid (BHBA) concentration.

Cure rate and case fatality rate: The cure rate and case fatality rate were evaluated based on the response to treatment.

\section{Results and Discussion}

The clinical signs observed in the sub clinical pregnancy toxaemic does were anorexia (100 per cent), dullness in 10 (83 per cent) and bruxism in 7 (58 per cent). All the does were in a standing posture with normal carriage of head and neck and normal voiding of dung. In the clinical pregnancy toxaemic does the clinical signs observed were anorexia (100 per cent), dullness (Fig. 9) in 10 (83 per cent), bruxism in 7 (58 per cent), scanty dung in 12 (100 per cent), acetone odour from mouth in 11 (92 per cent), standing posture in 6 (50 per cent), stargazing (Fig. 10) in 9 (67 per cent), sternal recumbency (Fig. 11) in 6 (50 per cent) and lateral deviation of neck (Fig. 12) in 5 (42 per cent).

The body condition score (BCS) was assessed using a 5 point scale (1.0 to 5.0$)$ at 0.5 increments and evaluated visually by palpating the region of lumbar vertebrae and sternum. The BCS of pregnant does in control group ranged between 2.5 to 3. Among the sub clinical pregnancy toxaemic does, eight (67 per cent) had a BCS of 2.0 while four (33 per cent) had BCS of 2.5 while in the clinical pregnancy toxaemic does, nine (75 per cent) had a BCS of 2.0 (Fig. 13) while three (25 per cent) had BCS of 2.5 (Fig. 14). The reason for the pregnancy toxaemic does to have a body condition score of 2.0 to 2.5 may be due to increased fat and protein catabolism as a result of severe under nutrition (Rook, 2000) ${ }^{[13]}$. Body condition score should be included for effective monitoring of feeding and herd health management for the development of a healthy and productive herd (Russel, 1984) ${ }^{[14]}$.

The $\beta$ - hydroxybutyric acid (BHBA) concentration in blood of control group ranged between $0.2 \mathrm{mmol} / \mathrm{l}$ to $0.4 \mathrm{mmol} / \mathrm{l}$ (Fig. 15), between $0.9 \mathrm{mmol} / \mathrm{l}$ to $1.5 \mathrm{mmol} / \mathrm{l}$ in subclinical pregnancy toxaemic does (Fig. 16) and between $2.1 \mathrm{mmol} / \mathrm{l}$ to $7.9 \mathrm{mmol} / \mathrm{l}$ in clinical pregnancy toxaemic does (Fig. 17) which were in accordance to Andrews (1997) [3] namely normal does $(<0.8 \mathrm{mmol} / \mathrm{l})$, subclinical form of pregnancy toxaemia $(0.8-1.6 \mathrm{mmol} / \mathrm{l})$ and clinical form of pregnancy toxaemia $>1.6 \mathrm{mmol} / \mathrm{l}$. The values obtained in the portable ketone meter were immediate, reliable and highly useful in screening does for pregnancy toxaemia on field conditions. The portable human ketone meter can be successfully applied to estimate beta hydroxybutyrate levels in field conditions due to the non availability of other reliable spot tests (Yadav et al, 2016) ${ }^{[19]}$.

Urinalysis of control group revealed absence of ketone bodies, glucose and protein while in pregnancy toxaemia, presence of ketone bodies, protein and glucose are diagnostic. Trace quantities of ketone bodies in the urine of 9 does $(75$ per cent) and small quantities in 3 does ( 25 per cent) of sub 
clinical pregnancy toxaemic group and trace in 2 (17 per cent), moderate in 2 (17 per cent), small in 4 (33 per cent) and large in 4 (33 per cent) observed in the clinical pregnancy toxaemic group might be due to the increased fat hydrolysis (Cleon, 1988) ${ }^{[6]}$. Protein was completely absent in the urine sample of sub clinical pregnancy toxaemic group while the protein grading were $1+$ in 3 does ( 25 per cent), $2+$ in 4 does ( 33 per cent) and $3+$ in 5 does ( 42 per cent) in the clinical pregnancy toxaemic group. The glucose grading were trace in 6 does ( 50 per cent) and $1+$ grading in 6 does ( 50 per cent) in the sub clinical group while the grading in clinical pregnancy toxaemic group were trace in 2 does (17 per cent), $1+$ in 1 doe ( 8 per cent), $2+$ in 5 does ( 42 per cent) and $3+$ in 4 does (33 per cent). The qualitative analysis of urine samples for the presence of ketone bodies, glucose and protein under field conditions can be carried out with accuracy and reliability using Multistix 10 SG reagent strips concurred with Emam and Galhoom (2008) ${ }^{[7]}$.

The does of sub clinical pregnancy toxaemic group responded to therapy and had a cure rate of 100 per cent. The distribution of cases in clinical pregnancy toxaemic group is presented in Table 1. Four does (33 per cent) were presented in sternal recumbency with lateral deviation of neck and were found to be $>140$ days pregnant with the aid of ultrasound. The fetal heart beat were completely absent in these four does which indicated fetal death. The blood beta hydroxybutyric acid and glucose levels were monitored using portable human blood ketone and glucose monitoring system which indicated blood beta hydroxybutyric acid concentration $>7 \mathrm{mmol} / \mathrm{L}$ (7.2 $\mathrm{mmol} / \mathrm{L}, 7.6 \mathrm{mmol} / \mathrm{L}, 7.8 \mathrm{mmol} / \mathrm{L}$ and $7.9 \mathrm{mmol} / \mathrm{L}$ respectively) and abnormally high glucose levels $(207 \mathrm{mg} / \mathrm{dL}$, $78 \mathrm{mg} / \mathrm{dL}, 76 \mathrm{mg} / \mathrm{dL}$ and $132 \mathrm{mg} / \mathrm{dL}$ respectively) (Fig. 18). The hyperglycaemia in advanced pregnancy toxaemic goats indicate foetal death and the reason were attributed to the removal of the suppressing effect of the foetus on hepatic gluconeogenesis (Wastney et al.,1983) ${ }^{[18]}$ and (Lima et al.,2012) ${ }^{[10]}$ or due to the increased serum cortisol level (Ford et al., 1990) ${ }^{[8]}$. They were resorted to treatment with intravenous glucose therapy ( 5 per cent Dextrose) supported with parenteral therapy of Vitamin $\mathrm{B}_{1}, \mathrm{~B}_{6} \& \mathrm{~B}_{12}$ and antihistaminic drug Chlorpheniramine maleate@ @ $0.5 \mathrm{mg} / \mathrm{kg}$ body weight intramuscularly on the day of presentation. However the owners were advised caesarean section to be performed in their does in order to save the dam. Two of the owners did not accept for caesarean section and decided to dispose off their animal, while the remaining two does died later in the evening before the owners accepted for the caesarean section. Caesarean section was the recommended treatment in advanced stages or in heavily pregnant does that did not respond well to treatment due to the high glucose demand or in fetal death to save the dam (Brounts et al., 2004) ${ }^{[5]}$ and (Lima et al., 2012) ${ }^{[10]}$. The remaining eight does (67 per cent) were in between 120 to 140 days of pregnancy. Among the eight, four had blood beta hydroxybutyric acid concentration of $3.6 \mathrm{mmol} / \mathrm{L}, 3.8 \mathrm{mmol} / \mathrm{L}, 5.2 \mathrm{mmol} / \mathrm{L}$ and $6.7 \mathrm{mmol} / \mathrm{L}$ respectively. Out of the four does, two had BHBA levels above $5 \mathrm{mmol} / \mathrm{L}$ and were presented in sternal recumbency and the one with BHBA level of $6.7 \mathrm{mmol} / \mathrm{L}$ had lateral deviation of the neck in addition to sternal recumbency. Both the does had a feeble fetal heart beat and were resorted to treatment with intravenous glucose therapy (5 per cent Dextrose) supported with parenteral therapy of Vitamin $\mathrm{B}_{1}, \mathrm{~B}_{6} \& \mathrm{~B}_{12}$. However both the does died on the next day. The remaining two which had blood beta hydroxybutyric acid concentration of $3.6 \mathrm{mmol} / \mathrm{L}$ and $3.8 \mathrm{mmol} / \mathrm{L}$ were presented in standing posture with stargazing. They were resorted to treatment with intravenous glucose therapy (5\% Dextrose) supported with parenteral therapy with Vitamin B1, B6 \& B12 and oral administration of glycerine for 3-4 days @ $25 \mathrm{ml}$ twice daily. These two does did not show much sign of recovery even after three days of therapy and hence the owners decided to disposed off their does.

The remaining four of the group (between 120 to 140 days of pregnancy) had blood beta hydroxybutyric acid concentration of $2.1 \mathrm{mmol} / \mathrm{L}, 2.2 \mathrm{mmol} / \mathrm{L}, 3.1 \mathrm{mmol} / \mathrm{L}$ and $3.5 \mathrm{mmol} / \mathrm{L}$ respectively. They were presented in standing posture with anorexia, dullness and bruxism. They were resorted to treatment with intravenous glucose therapy (5 per cent Dextrose) supported with parenteral therapy of Vitamin $\mathrm{B}_{1}, \mathrm{~B}_{6}$ $\& \mathrm{~B}_{12}$ and oral administration of glycerine for 3-4 days @ 25 $\mathrm{ml}$ twice daily. These does showed signs of recovery from third day of treatment in the form of alertness, improved feed intake and absence of bruxism. Out of the twelve does of clinical pregnancy toxaemic group only four does showed signs of improvement to therapy with a cure rate of 33 per cent, while mortality were present in four (33 per cent). The remaining four (33 per cent) did not show any signs of recovery to therapy and hence the owners decided to disposed off their does. In the present study the cure rate in clinical pregnancy toxaemic does were only 33 per cent as against 73 per cent (Balikci et al., 2009) ${ }^{[4]}$. The case fatality rate was 67 per cent as against 80 per cent (Andrews, 1997) ${ }^{[3]}, 86$ per cent (Lima et al., 2012) ${ }^{[10]}$ and 75 per cent (Lima et al., 2016) ${ }^{[11]}$ in prepartum hyperketonemic dairy does.

Table 1: Distribution of cases in clinical pregnancy toxaemic group $(n=12)$

\begin{tabular}{|c|c|c|c|c|c|c|}
\hline $\begin{array}{c}\text { Days of } \\
\text { Gestation }\end{array}$ & No of Does & Clinical signs & $\begin{array}{c}\text { BHBA } \\
(\mathrm{mmol} / \mathrm{L}) \\
\end{array}$ & $\begin{array}{c}\text { Blood Glucose } \\
(\mathrm{mg} / \mathrm{dL})\end{array}$ & Fetal Status & $\begin{array}{c}\text { Dam Recovery } \\
\text { Status } \\
\end{array}$ \\
\hline \multirow{4}{*}{$>140$ days } & \multirow{4}{*}{$\begin{array}{c}4 \\
\text { (33 per cent) }\end{array}$} & \multirow{4}{*}{$\begin{array}{l}\text { Sternal recumbency with } \\
\text { lateral deviation of neck }\end{array}$} & 7.2 & 207 & \multirow{2}{*}{ Dead } & \multirow{2}{*}{ Died } \\
\hline & & & 7.6 & 78 & & \\
\hline & & & 7.8 & 76 & \multirow{2}{*}{ Dead } & \multirow{2}{*}{ Disposed } \\
\hline & & & 7.9 & 132 & & \\
\hline \multirow{8}{*}{$120-140$ days } & \multirow{8}{*}{$\begin{array}{c}8 \\
\text { (67 per cent) }\end{array}$} & \multirow{2}{*}{$\begin{array}{c}\text { Standing posture with } \\
\text { stargazing }\end{array}$} & 3.6 & 27 & Alive & \multirow{2}{*}{ Disposed } \\
\hline & & & 3.8 & 22 & Alive & \\
\hline & & Sternal recumbency & 5.2 & 23 & \multirow[b]{2}{*}{$\begin{array}{c}\text { Feeble heart } \\
\text { beat }\end{array}$} & \multirow[b]{2}{*}{ Died } \\
\hline & & $\begin{array}{l}\text { Sternal recumbency with } \\
\text { lateral deviation of neck }\end{array}$ & 6.7 & 24 & & \\
\hline & & \multirow{4}{*}{$\begin{array}{l}\text { Standing posture, Anorexia, } \\
\text { Dullness, Bruxism }\end{array}$} & 2.1 & 21 & \multirow{4}{*}{ Alive } & \multirow{4}{*}{ Recovered } \\
\hline & & & 2.2 & 22 & & \\
\hline & & & 3.1 & 27 & & \\
\hline & & & 3.5 & 26 & & \\
\hline
\end{tabular}




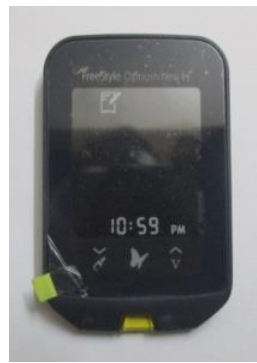

Fig 1: Portable Blood ketone monitoring system (Free Style Optium Neo H - Abbott ${ }^{\circledR}$ )

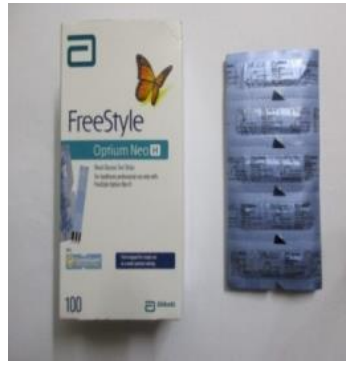

Fig 4: Blood Glucose Test Strip

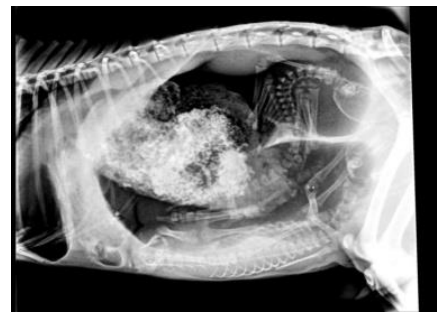

Fig 7: Radiography in pregnant doe - Twins

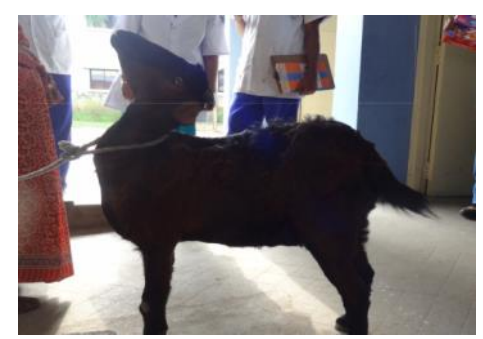

Fig 10: Star gazing

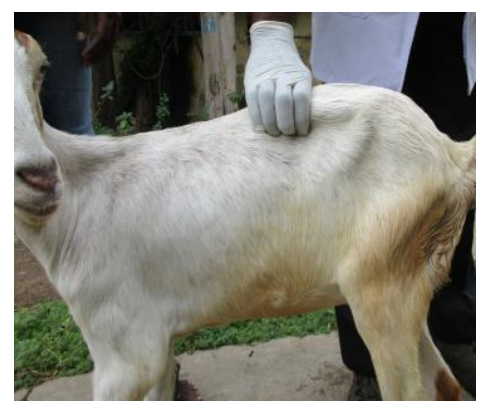

Fig 13: Body Condition Score 2.0

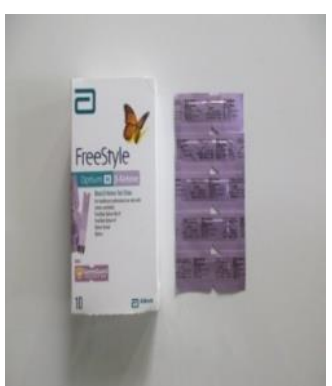

Fig 2: Blood $\beta$ - Ketone Test Strip

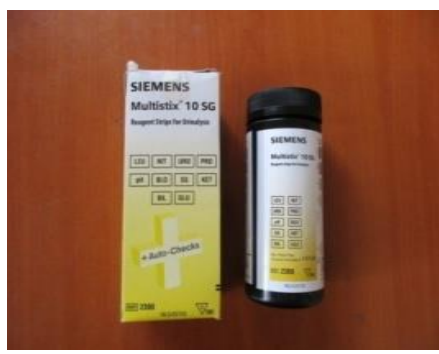

Fig 5: Urinalysis - Multistix 10SG reagent strip (Siemens Healthcare Pvt. Ltd.)

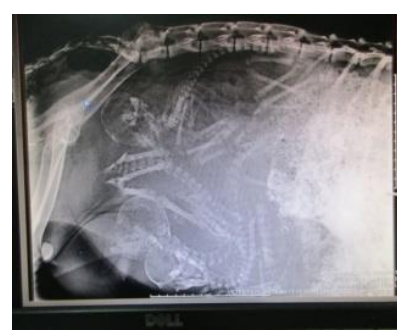

Fig 8: Radiography in pregnant doe - Triplets

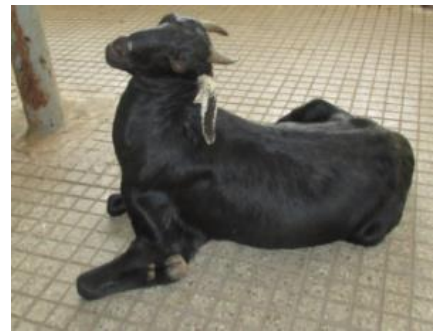

Fig 11: Sternal recumbency with Star gazing

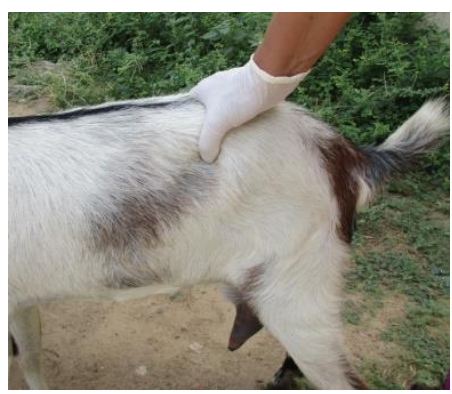

Fig 14: Body Condition Score 2.5

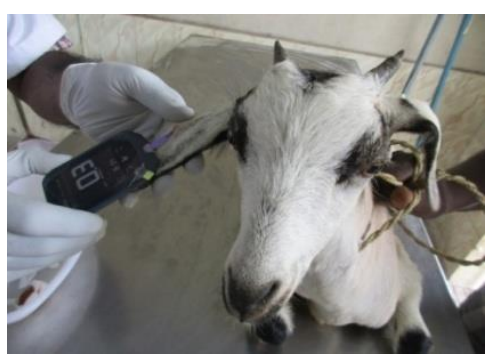

Fig 3: Recording of blood $\beta$-hydroxybutyric acid concentration

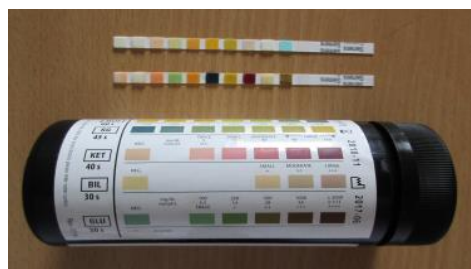

Fig. 6: Urinalysis using Multistix 10SG reagent strip in Pregnancy Toxaemic Doe

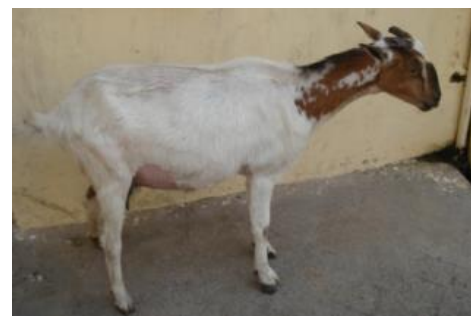

Fig 9: Dullness

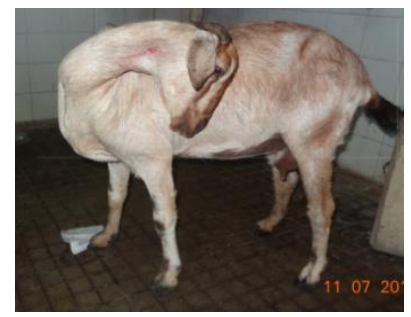

Fig 12: Standing posture with lateral deviation of neck

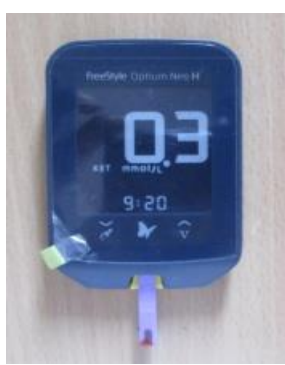

Fig 15: Blood $\beta$ - hydroxybutyric acid concentration in does of control group 


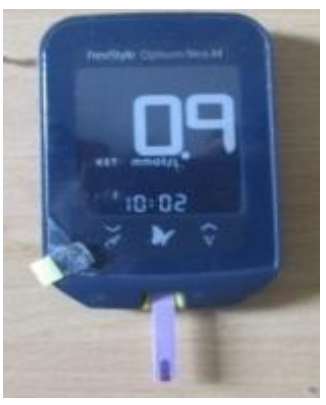

Fig 16: Blood $\beta$-hydroxybutyric acid concentration in Sub Clinical Pregnancy Toxaemic Doe

\section{Conclusion}

On field diagnostic and prognostic indicators of pregnancy toxaemia are the need of the hour for better herd health management. The recovery rates were better when the therapy was initiated in the early stage of the disease compared to the advanced stages of the disease. Early indicators of pregnancy toxaemia include presence of ketone body in the urine and blood $\beta$-hyroxybutyric acid concentration $(\geq 0.8 \mathrm{mmol} / \mathrm{l})$ while hyperglycaemia in advanced pregnancy toxaemic indicate foetal death. Hence determination of blood $\beta$ hydroxybutyric acid (BHBA) and glucose concentration using portable blood ketone / glucose meter and qualitative urinalysis using urine dip stick for the presence of ketone bodies are the reliable indicators in the diagnosis of pregnancy toxaemia under field conditions.

\section{References}

1. Abdelghafar RM, Ahmed BM, Ibrahim MT, Mantis P. Prediction of gestational age by transabdominal real time ultrasonographic measurements in Saanen goats (Capra hircus). Global Veterinaria 2011;6:346-351.

2. Albay MK, Karakurum MC, Sahinduran S, Sezer K, Yildiz R. Selected serum biochemical parameters and acute phase protein levels in a herd of Saanen goats showing signs of pregnancy toxaemia. Vet. Med 2014;59:336-342.

3. Andrews A. Pregnancy toxaemia in the ewe. In Pract 1997; 19:306-312.

4. Balikci E, Yildiz A, Gurdogan F. Investigation on some biochemical and clinical parameters for pregnancy toxaemia in Akkaraman ewes. J. Anim. Vet. Adv 2009;8:1268-1273.

5. Brounts SH, Hawkins JF, Baird AN, Glickman LT. Outcome and subsequent fertility of sheep and goats undergoing cesarean section because of dystocia: 110 cases (1981-2001). J. Am. Vet. Med. Assoc 2004;224:275-281.

6. Cleon VK. Disease of Sheep. $3^{\text {rd }}$ ed., Lea and Febiger, Philadelphia, U.S.A 1988, 23-46.

7. Emam EE, Galhoom KI. Hormonal, haematological blood biochemical changes in pregnancy toxaemia in Balady goats (Caprines caprina) with trials of treatment as a field study. Egypt J. Comp. Pathol. Clinic. Pathol 2008;21:121-138.

8. Ford EJ, Evans J, Robinson I. Cortisol in pregnancy toxaemia of sheep. Br. Vet. J 1990;146:539-542.

9. Hefnawy AE, Shousha S, Youssef S. Hematobiochemical profile of pregnant and experimentally pregnancy toxemic goats. J. Basic Applied Chem 2011;1:65-69.

10. Lima MS, Pascal RA, Stilwell GT. Glycaemia as cal Pregnancy Toxaemic

Doe

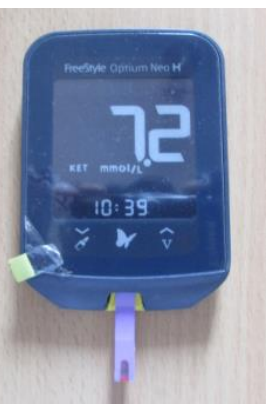

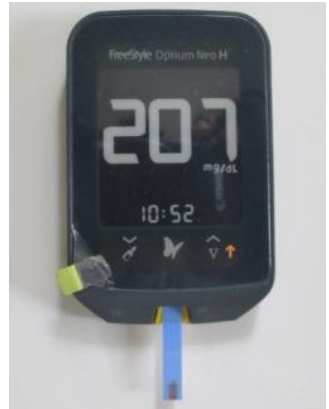

Fig 18: Blood Glucose concentration in Clinical pregnancy toxaemic group a sign of the viability of the foetuses in the last days of gestation in dairy goats with pregnancy toxemia. Ir. Vet. J 2012;65:136-148.

11. Lima MS, Silveira JM, Carolino N, Lamas LP, Pascoal RA, Hjerpe CA. Usefulness of clinical observations and blood chemistry values for predicting clinical outcomes in dairy goats with pregnancy toxaemia. Ir. Vet. J 2016;69:16-24.

12. Pichler M, Damberger A, Amholdt T, Schwendenwein I, Gasteiner J. Evaluation of 2 electronic handheld devices for diagnosis of ketonemia and glycemia in dairy goats. J. Dairy Sci 2014;97:7538-7546.

13. Rook JS. Pregnancy toxemia of ewes, does, and beef cows. Vet. Clin. Nr. Am. Food Anim. Pract 2000;16:293317.

14. Russel A. Body condition scoring of sheep. In Pract 1984;6:91-93.

15. Schlumbohm C, Harmeyer J. Twin pregnancy increases susceptibility of ewes to hypoglycemic stress and pregnancy toxemia. Res. Vet. Sci 2008;84:286-299.

16. Van Saun RJ. Pregnancy toxemia in a flock of sheep. J Am. Vet. Med. Assoc 2000;217:1536-1539.

17. Villaquiran M, Gipson R, Merkel R, Goetsch A, Sahlu T. Body condition scores in goats. Agriculture Research and Cooperative Extension. Langston University, Langston 2012.

18. Wastney ME, Wolf JR, Bickerstafle R. Glucose turnover and hepatocyte glucose production of starved and toxaemic pregnant sheep. Aust. J. Biol. Sci 1983;36:271284.

19. Yadav SN, Kalita DN, Phukan A, Tamuly S, Dutta TC, Mahato G, et al. Diagnosis of caprine ketosis using human hand held ketone meter. Bangl. J Vet. Med 2016;14:179-181. 